\title{
WAIST-TO-HEIGHT RATIO (WTHR): PROPOSED APPROACH TO ESTABLISHING REFERENCE VALUES FOR CHILDREN AND YOUTHS
}

\author{
Romuald Stupnicki, Pawel Tomaszewski, Katarzyna Milde, \\ Joanna Glogowska, Helena Poplawska \\ University of Physical Education in Warsaw, Poland
}

\begin{abstract}
Detection of central obesity is usually based on the criterion represented by the waist-to-height ratio $(\mathrm{WtHR}) \geq 0.50$. However, that criterion has been disputed, especially in the period of growth. Since obesity cannot be reasonably defined without involving body fat content $(\% \mathrm{~F})$, the aim of the study was to establish gender- and age-specific reference WtHR values for children and youths selected for an acceptable \%F. In cohorts of 1193 boys and 1307 girls, aged 7-20 years, body fat content was determined from 3 skinfolds (triceps, subscapular, abdominal) using Slaughter's equations. Next, 505 boys and 396 girls with acceptable fat percentage were selected and for them log WtHR values were computed. The equations for log WtHR values vs. age (a) were: $\left(-0.31-0.01264 a+0.000476 a^{2}\right) \pm 0.0283$ for boys and $(-0.268-0.02047 a+0$ $\left..00073 \mathrm{a}^{2}\right) \pm 0.0344$ for girls. Upper WtHR limits (means $\left.+2 \mathrm{SD}\right)$ attained minimum values $(0.460$ and 0.454$)$ in the age range of $12-15$ years. When applying that criterion to subjects with excessive $\% \mathrm{~F}, 14.3 \%$ of all boys and $18.2 \%$ of girls were classified as centrally obese, but only 8.5 and $9.3 \%$, respectively, when the $\mathrm{WtHR}=0.50$ criterion alone was used. Cut-off values for WtHR indicating central obesity are markedly lower than 0.50 especially in the adolescence period and can be applied only to subjects with excessive fat percentage.
\end{abstract}

Keywords: obesity, body fat content, waist-to-height ratio, reference values 


\section{INTRODUCTION}

The incidence of overweight and obesity of children steadily increases to an epidemic degree in developed countries $[6,10,15]$. Untreated obesity in the childhood brings about many health disorders in the adult age [12, 23]. This applies, in particular, to central (abdominal) obesity that induces arterial hypertension, type 2 diabetes, dyslipidemia, metabolic syndrome, or ischaemic heart disease $[4,7,8,13]$.

Screening for overweight and obesity in children is based on the widely used anthropometric indices [5], one of the most popular ones being BMI. However, $\mathrm{BMI}$ is useless in assessing the body fat content and its distribution [17] which is vital for detecting central obesity. For that reason, other indices, like waist circumference (WC) and waist-to-height ratio (WtHR) gain popularity in assessing the risk of cardiovascular diseases [24, 14, 21]. That latter index (WtHR) seems especially valuable since the waist circumference alone may be imprecise in the case of subjects of extreme stature [2].

Many authors recommend using a central obesity criterion represented by $\mathrm{WtHR} \geq 0.50$, the same for men and women. That criterion has been, however, disputed, especially in the period of growth when the gains in body height and waist circumference may not parallel one another [22]. Moreover, the use of an identical criterion for both genders has been questioned [22].

Establishing reference WtHR values for children and youths may be of prime importance in an assessment of their development. It seems that such reference values ought to be gender- and age-specific, thus enabling a more precise assessment of central obesity compared with the standard value equal to 0.50 . Since obesity is associated with an excess of body fat content, such reference values ought to be based on data recorded in subjects having a non-excessive fat content. The aim of the study was thus to establish the WtHR reference values for children and youths aged 7-20 years and to present the approach to them.

\section{MATERIAL AND METHODS}

The study was conducted in 18 randomly selected schools in eastern and central Poland. The studied cohort counted 1193 boys and 1307 girls, aged 7-20 years. The study was conducted in accordance with the Helsinki declaration and was approved by the local Committee of Ethics. 
The following data were recorded: exact calendar age, body height and mass measured with a stadiometer (HOLTAIN, UK; accuracy $0.1 \mathrm{~cm}$ ) and medical scales (TANITA, Japan; accuracy $0.1 \mathrm{~kg}$ ), respectively. Waist circumference was measured using an anthropometric tape (SECA, Germany) at the navel level and hip width was measured using a wide sliding calliper (HOLTAIN, UK). Three skinfolds (triceps, subscapular, abdominal) were measured using a skinfold calliper (HOLTAIN, UK; accuracy $0.1 \mathrm{~mm}$ ). Relative body fat content was determined from skinfold measurements using Slaughter's equations [16].

The following procedure was used to compute z-values for the percentage of body fat content: the previously established lower and upper, gender- and agedependent limits of a reasonable fat content [18] were log means \pm 2 SD resulting in following equations of means $\pm \mathrm{SD}$ vs. age:

$$
\begin{aligned}
& \text { Boys: } \log \% \mathrm{~F}=\left(0.837+0.05464^{\mathrm{a}}-\right. \\
& \left.0.0023955 a^{2}+0.0000378 a^{3}\right) \pm\left(0.0094+0.00951^{a}-0.0005983 a^{2}+0.0000115 a^{3}\right. \text {; }
\end{aligned}
$$$$
\begin{gathered}
\text { Girls: } \log \% \mathrm{~F}=\left(0.8578+0.0589^{\mathrm{a}}-0.002639 \mathrm{a}^{2}+0.0000399 \mathrm{a}^{3}\right) \pm(0.0634- \\
\left.0.00731 \mathrm{a}+0.000773 \mathrm{a}^{2}-0.00003292 \mathrm{a}^{3}+0.00000049 \mathrm{a}^{4}\right)
\end{gathered}
$$

The data of the relative body fat content $(\% \mathrm{~F})$ were standardised using the age functions of means and standard deviations of $\% \mathrm{~F}$ and then classified into four categories: decreased body fat (DF; $\mathrm{z}<-2.5$ ), normal body fat (NF; $\mathrm{z}$-values ranging from -2.5 to 2.0 ), excess body fat (EF; z-values ranging from above 2.0 to 4.04 in boys or to 4.23 in girls, and obesity (OB; above the latter values). The standardised cut-off values for body fat content corresponded to those for $\mathrm{BMI}=30$ according to norms [18] and amounted to 23.7 and $24.1 \%$ in boys and girls aged 19 years, respectively. The NF category contained 505 boys and 396 girls and the data of those subjects served to compute the reference WtHR values.

Data analysis: The values of body height, waist circumference, hip width and relative body fat content were converted to logarithms prior to analysis. The data of subjects having normal body fat content (NF category) were arranged by age (for waist circumference vs. age) or by body height (for hip width vs. body height) and divided into categories of $n=100$ each in an overlapping way, e.g. first category contained data 1-100, the second one 51-150, etc. [cf. 19]. For every category, mean values of the respective variables were 
computed. Those means served to compute regression equations and the respective regression errors. Pearson's correlation coefficients, multiple correlations and percent contributions of those variables to the total WtHR variance were computed [cf. 20]. The frequencies were assessed by using the chi-square function. The level of $\mathrm{p} \leq 0.05$ was considered significant.

\section{RESULTS}

Based on the data of subjects having normal body fat content, the following WtHR equations vs. age, and the respective regression errors were obtained:

Boys: $\log W t H R=\left(-0.31-0.01264 a+0.000476 a^{2}\right) \pm 0.0283$

Girls: $\log \mathrm{WtHR}=\left(-0.268-0.02047 \mathrm{a}+0.00073 \mathrm{a}^{2}\right) \pm 0.0344$

The proposed reference values obtained from those equations reconverted from logarithms are presented in Fig. 1.

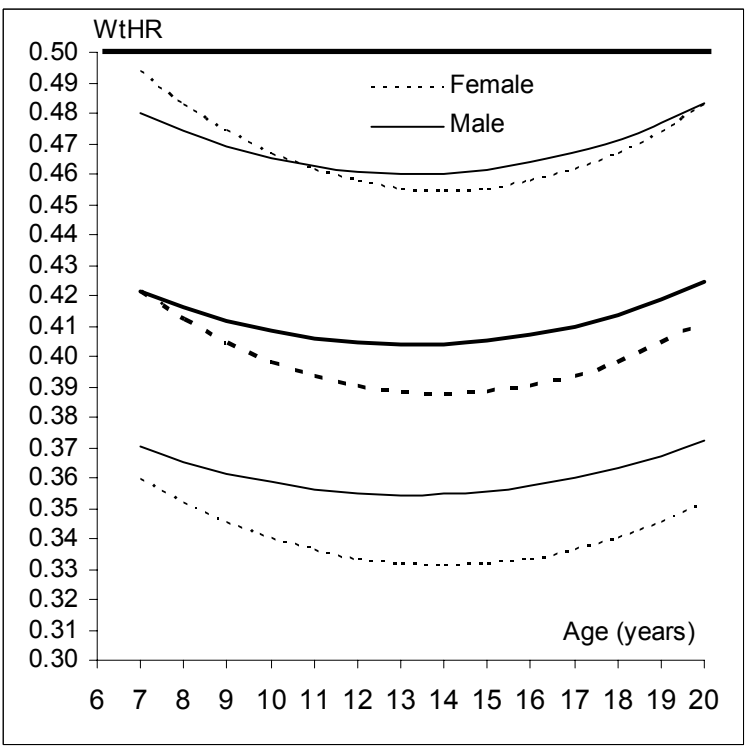

Figure 1. Mean values of the waist-to-height ratio $\pm 2 \mathrm{SD}$ established for boys $(n=505)$ and girls $(n=396)$ with "normal" body fat content

The upper limit of WtHR values shows a distinct minimum in the age range $12-15$ or $13-15$ years and amounting respectively to 0.460 in boys and to 0.454 in girls. The logarithmic equations were used to standardise WtHR values 
recorded in all subjects. Those with excessive body fat content were further classified with respect to WtHR - values below the upper limit were considered to indicate peripheral fat distribution while values above the upper limit indicated central (abdominal) fat deposition. The percentages of subjects classified by the excess of body fat content and its distribution are shown in Fig. 2.

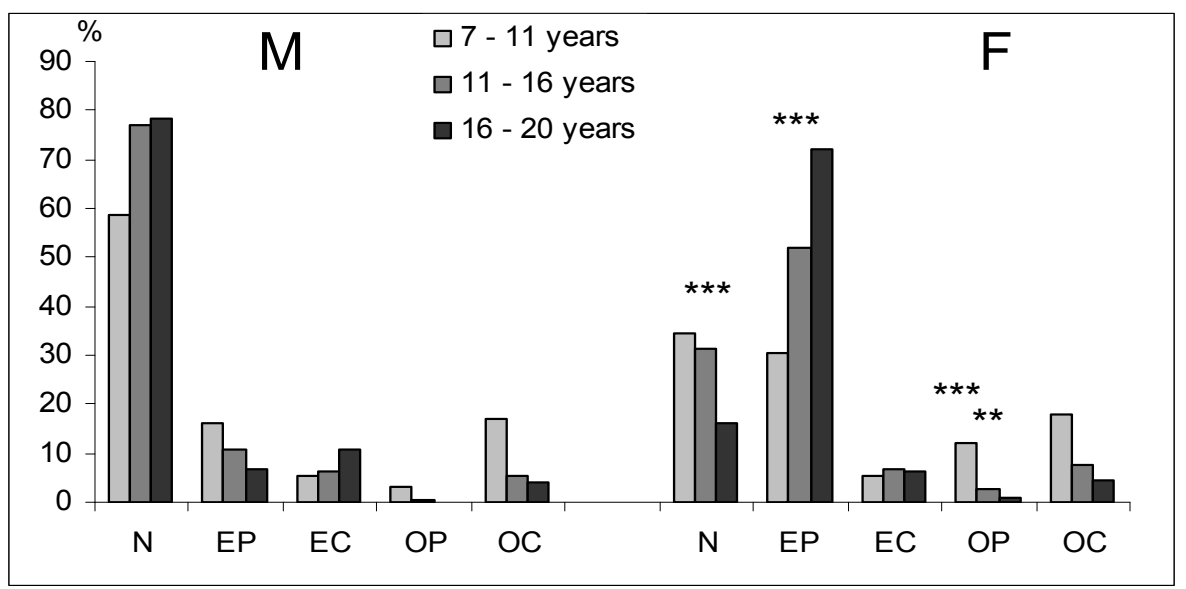

Fig. 2. Percentages of boys $(M)$ and girls $(F)$, classified as having "normal" body fat content $(N)$, excess fat $(E)$ or obese $(O)$, fat being distributed peripherally $(P)$ or centrally $(C)$ in 3 age categories. Significantly different from boys: ${ }^{* *} p<0.01$; ${ }^{* * *} p<0.001$; in all cases (except EC in girls) the age-related trends were significant $(p<0.01-0.001)$.

Generally, significantly $(\mathrm{p}<0.001)$ more girls than boys had excessive fat distributed peripherally. No such difference was found for the central distribution of fat. The frequency of obesity significantly $(p<0.001)$ decreased with age in boys and girls, and the same was true for the excessive peripheral fat distribution in boys. On the other hand, excessive, peripheral fat distribution in girls $(\mathrm{p}<0.001)$ and central fat distribution in boys $(\mathrm{p}<0.01)$ significantly increased with age.

The obtained results were compared with those resulting from classifying subjects by BMI using the cut-off points proposed by Cole et al. [3] and the $\mathrm{WtHR}=0.50$ criterion (Fig. 3 ). 

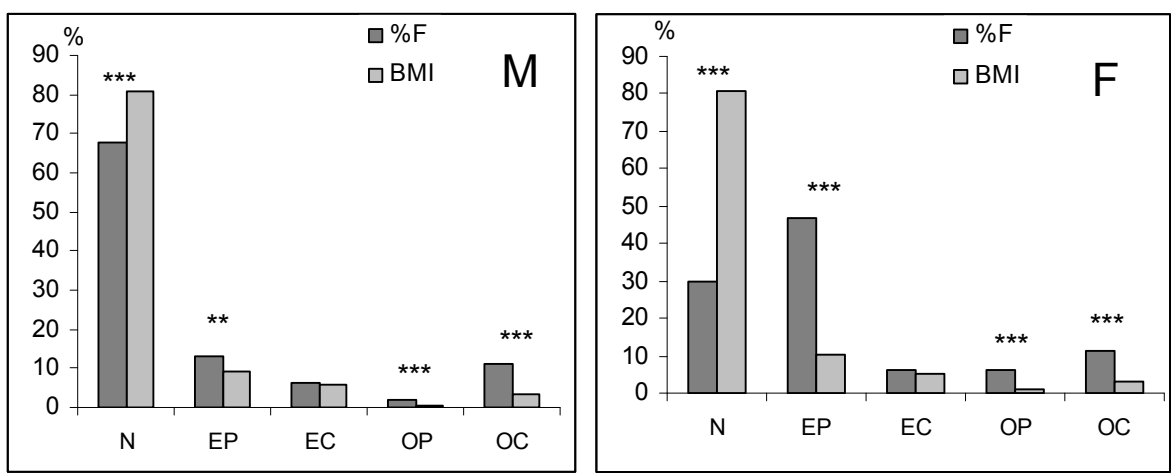

Fig. 3. Percentages of boys $(n=1193)$ and girls $(n=1307)$ classified as having acceptable body fat content $(N)$, excess fat $(E)$ or obese $(O)$, fat being distributed peripherally $(P)$ or centrally $(\mathrm{C})$ by applying the criterion of body fat content $(\% \mathrm{~F})$ or BMI cut-off [3] plus $\mathrm{WtHR}=0.50(\mathrm{BMI}) . \mathrm{N}-$ Normal range of body fat content or BMI; significant differences between bars representing \%F and BMI: ${ }^{* \star} p<0.01$; ${ }^{* \star *} p<0.001$; for explanation of other symbols see Figure 2 .

The most striking differences were noted in the frequencies of central obesity: classification by BMI and WtHR rendered only $3.5 \%$ in boys and $2.8 \%$ in girls, while by body fat content and WtHR as much about $11.2 \%$ in both genders. In that respect, the differences in classifying girls as "normal" or as peripherally excessive in the fat content or BMI are less important. In addition, the percentages of subjects classified as centrally excessive (including obese) by the $\mathrm{WtHR}=0.50$ criterion or by our criteria ( $\mathrm{z} \% \mathrm{~F}$ and $\mathrm{z}$ WtHR$)$ amounted to 8.5 and 14.3, respectively, in boys and to 9.3 and 18.2, respectively, in girls.

Since WtHR might be affected by body fat content as well as by body proportions, the respective multiple correlations combined with percent contributions of those variables to the total WtHR variance were computed (Table 1).

In order to eliminate the effects of age and body height, all three variables were taken as the respective standardised values: WtHR and \%F vs. age using the equations presented above and hip width (HW) using allometric equations vs. body height $(\mathrm{BH})$ :

Boys: $\log \mathrm{HW}=1.241 \log \mathrm{BH}-1.281 \pm 0.030$

Girls: $\log H W=1.4895 \log \mathrm{BH}-1.802 \pm 0.033$ 
As much as $60 \%$ of the total WtHR variance could be attributed to body fat content (50\%) and hip width (10\%) in boys, and $43 \%$ of the WtHR variance in girls, the contributions of $\% \mathrm{~F}$ and $\mathrm{HW}$ amounting to 27 and $16 \%$, respectively. All those values were highly significant $(\mathrm{p}<0.001)$.

Table 1. Multiple correlation coefficient $\left(R^{2}\right)$ and percent contributions of body fat content $(\mathrm{F} \%)$ and hip width to the total variance of waist-to-height ratio (WtHR)

\begin{tabular}{lcc}
\hline & $\begin{array}{c}\text { Boys } \\
\mathbf{n}=\mathbf{1 1 9 3}\end{array}$ & $\begin{array}{c}\text { Girls } \\
\mathbf{n}=\mathbf{1 3 0 7}\end{array}$ \\
\hline $\mathrm{R}^{2}$ & $0.598^{\star \star *}$ & $0.430^{\star \star *}$ \\
\hline Body fat content & $50 \% \%^{\star \star *}$ & $27 \% \%^{\star \star \star}$ \\
\hline Hip width & $10 \% \%^{\star \star *}$ & $16 \% \%^{\star \star \star}$ \\
\hline
\end{tabular}

Explanations: WtHR and F\% values were z-scores of their logarithmic age functions; hip width values were $z$-scores of the allometric relation to body height; ${ }^{* * *} p<0.001$

\section{DISCUSSION}

An objective assessment of the incidence of central obesity in children and youths is difficult due to a variety of criteria used to define obesity. The cut-off points for various anthropometric indices are usually derived from population data, e.g. percentiles, age- and gender-specific. However, such percentile data reflect the population status and cannot serve as recommended norms. Cole et al. [3] considered body fat content the ideal definition of overweight and obesity, however impractical epidemiologically, and proposed normal ("cut-off") values of BMI for children and youths prepared by adjusting the existing data to the values recommended by the WHO for adults.

The presented approach to assessing body fat distribution offers an improvement to the widely used procedures. The design of normal limits, i.e. of reference values, was based on data recorded in those children and youths, whose body fat content was considered physiologically reasonable. Although body fat content was expressed in standardised units $(\mathrm{z})$, the presented equations for computing those z-values ought not to be regarded as "norms", for no commonly accepted norms for body fat content exist. Nevertheless, those physiologically reasonable values seem sufficient for the purpose of designing normal values for weight-height relationships like BMI, WtHR, etc., since increasing or decreasing the limits of body fat content by $0.3 \mathrm{SD}$ rendered practically the same normal values for BMI and WtHR and the same was true for 
the technique of determining body fat content. This is of practical importance since various approaches to the assessment of body fat content may render different estimations.

The WtHR index has been used to detect the risk of obesity; the most commonly applied critical value of that index is equal to 0.50 irrespectively of age and gender, values exceeding 0.6 being considered alarming [1]. Like mentioned in the Introduction, such a uniform criterion was questioned by Tybor et al. [22] who tried to optimize the WtHR cut-off values by using allometric equations. They found the regression slope of log waist circumference vs. $\log$ body height, i.e. the exponent of body height to be used in computing WtHR values, to exceed 1 in children aged 6-13 years. No age-related differences of that exponent were found in this study for subjects with "normal" body fat content and the overall values amounted to 0.964 and 0.692 for boys and girls, respectively.

The presented normal limits for WtHR provide a sensitive approach to detect central obesity in growing subjects as the upper limit, defined as mean $\pm 2 \mathrm{SD}$, i.e. corresponding to percentile 99.7 , is lower than the generally accepted value 0.5 over the entire age range 7-20 years. The minimum observed at the age of 12-15 years coincides with the age range of the growth spurt when the upward growth prevails over the gain of body mass. The presented approach is also simpler to apply than that suggested by Tybor et al [22].

In this study, WtHR values were generally higher in boys than in girls. Similar results were reported by McCarthy and Ashwell [11] who found higher values in British boys aged 5-16 years than in girls over the study period 1977-1997, while in the National Health and Nutrition Examination Survey (1999-2004), [9] girls consistently had slightly higher values of WtHR index across all age groups; these discrepancies may be attributed to populationrelated differences in obesity incidence.

By applying the criteria described above, central obesity was noted in $11.2 \%$ of all boys and in $11.3 \%$ of girls (no significant difference). When this was combined with subjects who were not yet obese $(z<3.7$ or $<4.5$ in boys and girls, respectively) but had excessive body fat content $(\mathrm{z}>2.0)$, the respective percentages amounted to 17.6 and 17.3, and when the WtHR criterion of $\mathrm{WtHR}=0.5$ was applied to all the subjects, those percentages amounted to 10.2 and 9.1, respectively (no significant difference). In contrast, Li et al [9] found central obesity to be more frequent in girls than in boys -30 and $27 \%$ in the 
age range of 6-11 years and about 49 and $36 \%$ in the age range of $18-19$ years, respectively.

Since obesity is the result of an excessive fat deposit, the first step is an assessment of body fat content. In growing subjects in whom the body fat content is higher than reasonable the WtHR may indicate the type of fat distribution - when the value is within normal limits, a relatively uniform, peripheral fat distribution is assumed. When fat is accumulated centrally, which is considered a risk factor in cardiovascular diseases, the WtHR value exceeds the upper normal limit.

As shown in this study, the WtHR depends to some extent on body frame reflected by hip width. The latter may thus serve as an additional factor when assessing the risks associated with adiposity. Namely, when the body fat content is above average but within reasonable limits for age $(z<2)$ and the WtHR value is increased $(z>2)$, subjects with narrow hips $(z<-1.65$ corresponding to Percentile 5) may fall into the category of potential central adiposity. The same applies to non-obese subjects but with increased adiposity classified as having peripheral fat distribution; when their hips are narrow, central fat deposition may be suspected.

Summing up, the presented reference values of WtHR seem to constitute a better criterion of detecting central obesity in children and youths than either the uniform value of 0.5 or cut-off points established from data recorded in the entire, unselected population. Application of the presented values, which are lower than 0.5 , especially in the intense growth period, would bring about the detection of central obesity and the associated health risks in a much higher percentage of youths, thus enabling the undertaking of adequate preventive measures provided they are combined with measuring body fat content. Thus, when applying the $\mathrm{WtHR}=0.50$ criterion alone, only 8.5 and $9.3 \%$ of boys and girls, respectively, were classified as centrally obese but when applying the here presented upper normal value (mean for age+2SD) to subjects with excessive $\% \mathrm{~F}$, those percentages increased to $14.3 \%$ of boys and $18.2 \%$ of girls.

In conclusion, the cut-off values for WtHR, indicating central obesity are markedly lower than 0.50 , the generally accepted value for adults, especially in the adolescence period. Those cut-off values can be applied only to subjects in whom an excessive body fat content was found, except when BMI equals 30 or more. 


\section{REFERENCES}

1. Ashwell M. (2009). Obesity risk: importance of the waist-to-height ratio. Nurs Stand, 23, 41, 49-54.

2. Browning L. M., Hsieh S. D., Ashwell M. (2010). A systematic review of waist-toheight ratio as a screening tool for the prediction of cardiovascular disease and diabetes: 0.5 could be a suitable global boundary value. Nutr Res Rev, 23, 247-269.

3. Cole T. J., Bellizzi M. C., Flegal K. M., Dietz W. H. (2000). Establishing a standard definition for child overweight and obesity worldwide: international survey. BMJ, 320, 1240-1243.

4. Hirschler V., Aranda C., Calcagno Mde. L., Maccalini G., Jadzinsky M. (2005). Can waist circumference identify children with the metabolic syndrome? Arch Pediatr Adolesc Med, 159, 8, 740-744.

5. Hoffmann K., Bryl W., Marcinkowski J. T., Strażyńska A., Pupek-Musialik D. (2011). Estimation of physical activity and prevalence of excessive body mass in rural and urban Polish adolescents. Ann Agric Environ Med, 18, 2, 398-403.

6. James P. T. (2004). Obesity: the worldwide epidemic. Clin Dermatol, 22, 4, 276-280.

7. Janssen I., Katzmarzyk P. T., Srinivasan S. R., Chen W., Malina R. M., Bouchard C., Berenson G.S. (2005). Combined influence of body mass index and waist circumference on coronary artery disease risk factors among children and adolescents. Pediatrics, 115, 1623-1630.

8. Lee S., Bacha F., Gungor N., Arslanian S. A. (2006). Waist circumference is an independent predictor of insulin resistance in black and white youths. J Pediatr, $148,188-194$.

9. Li C., Ford E. S., Mokdad A. H., Cook S. (2006). Recent trends in waist circumference and waist-height ratio among US children and adolescents. Pediatrics, 118, 5, 1390-1398.

10. Lobstein T. J., James W. P., Cole T. J. (2003). Increasing levels of excess weight among children in England. Int J Obes Relat Metab Disord, 27, 9, 1136-1138.

11. McCarthy H. D., Ashwell M. (2006). A study of central fatness using waist-toheight ratios in UK children and adolescents over two decades supports the simple message - 'keep your waist circumference to less than half your height. Int J Obes, 30, 6, 988-992.

12. Must A., Strauss R. S. (1999). Risks and consequences of childhood and adolescent obesity. Int J Obes Relat Metab Disord, (Suppl 2), 23, S2-11.

13. Rasouli N., Kern P. A. (2008). Adipocytokines and the metabolic complications of obesity. J Clin Endocrinol Metab, (11 Suppl 1), 93, S64-73.

14. Savva S. C., Tornaritis M., Savva M. E., Kourides Y., Panagi A., Silikiotou N., Georgiou C., Kafatos A. (2000). Waist circumference and waist-to-height ratio are better predictors of cardiovascular disease risk factors in children than body mass index. Int J Obes, 24, 1453-1458. 
15. Seidell J. C. (2005). Epidemiology of obesity. Semin Vasc Med, 5, 1, 3-14.

16. Slaughter M. H., Lohman T. G., Boileau R. A., Horswill C. A., Stillman R. J., Van Loan M. D., Bemben D. A. (1988). Skinfold equations for estimation of body fatness in children and youth. Hum Biol, 60, 5, 709-723.

17. Soto González A., Bellido D., Buño M. M., Pértega S., De Luis D., MartínezOlmos M., Vidal O. (2007). Predictors of the metabolic syndrome and correlation with computed axial tomography. Nutrition, 23, 1, 36-45.

18. Stupnicki R., Milde K., Przewęda R. (2001). Constructing growth reference curves. Papers Anthropol, 10, 268-279.

19. Stupnicki R., Tomaszewski P., Milde K., Czeczelewski J., Lichota M., Głogowska J. (2009). Body fat-based weight norms for children and youths. Pediatr Endocrinol Diabetes Metab, 15, 3, 139-143.

20. Stupnicki R., Tomaszewski P., Milde K. (2007). Contributions of age, body height and body mass to the total variance of an example physical fitness variable. Papers Anthropol, 16, 266-272.

21. Taylor R. W., Jones I. E., Williams S. M., Goulding A. (2000). Evaluation of waist circumference, waist-to-height ratio, and the conicity index as screening for high trunk fat mass, as measured by dual - energy X-ray absorptiometry, in children aged 3-19 y. Am J Clin Nutr, 72, 2, 490-495.

22. Tybor D. J., Lichtenstein A. H., Dallal G. E., Must A. (2008). Waist-to-height ratio is correlated with height in US children andadolescents aged 2-18 years. Int J Pediatr Obes, 3, 3, 148-151.

23. Whitaker R. C., Wright J. A., Pepe M. S., Seidel K. D., Dietz W. H. (1997). Predicting obesity in young adulthood from childhood and parental obesity. $\mathrm{N}$ Engl J Med, 337, 869-873.

24. Zatońska K., Janik-Koncewicz K., Regulska-Ilow B., Ilow R., Różańska D., Szuba A., Einhorn J., Vatten L., Xiao-Mei M., Janszky I., Paprzycki P., Sulkowska U., Goździewska M., Mańczuk M., Zatoński W. A. (2011). Prevalence of obesity baseline assessment in the prospective cohort 'PONS' study. Ann Agric Environ Med, 18, 2, 246-250.

\section{Address for correspondence:}

Romuald Stupnicki

Stryjenskich 10-199.02-791 Warsaw Poland

E-mail: rstupnicki@auf.edu.pl 